\title{
Sonia's Story
}

Moira Fraser Juliebo

University of Alberta

Who is responsible for a child's successful entry into and fruitful continuance in school? Too often, if a child's social behavior does not conform to that required in the classroom, we as teachers begin a search for causes. By labeling the child socially disruptive, we place the responsibility for nonconformity squarely in the lap of the child. We offer blame, not help. Our expectations for that child are immediately lowered. Yet we retain the possibility of help if we are aware of the experiences the child has had to facilitate his or her social growth in partnership with parents and seek ways to enhance this growth.

For most young children, kindergarten is their first experience of formal education and may have a profound influence on their attitudes to schooling. I think it is crucial that teachers, parents, and students work in harmony to facilitate as smooth a transition from home to school as possible. In this anxious world of today, there is a need to nourish inner strength in our students so that they see themselves as artful, creative, and empowered to confront the meaning of life. For one child, Sonia, whom I observed in a kindergarten setting and at home over a 15-month period, conformity to the classroom setting was problematic, and her behavior provoked a critical response to the needs of one child to express her humanness and the role of parents and teachers in the process.

\section{Sonia's Portrait}

Sonia lived with her mother Catherine and stepfather Gerry in an apartment near the local school. She spent most of her waking hours in the company of these adults who adored her. Catherine said, "I think she is going to love kindergarten. I hope the teacher will take time to find out what she is like and understand her." Perhaps the parents sensed that the world did not love her as they did. The parents felt that by reading to her before birth and constantly afterward she would develop a love for books. Although she did not own many books, weekly visits to the library provided a plethora of delights. Book sharing and conversations were often initiated by Sonia and were 
pervaded by fun and spontaneous conversations. Catherine constantly encouraged her to read along with her and to predict texts from pictures. New words were explained carefully and related to her own life experience. Sonia was constantly encouraged to display her own knowledge by retelling favorite stories. Catherine said, "Sonia looks at pictures and tells the story and they both jive together."

Sonia also wrote a great deal, copying words, pretend writing, and making letter inventories. She also often labeled her art works. Catherine, like many mothers, was somewhat unaware of her vital role in her child's literacy development. She felt as far as reading was concerned that she was a rotten mother: "I don't have the patience or the know-how to really teach her." Reading seemed to be primarily for emotional pleasure and was not seen as something she could teach. Catherine implied that teaching was for teachers. Her comment about being a rotten mother would seem to suggest that teaching reading was different from what she and Sonia did with books. Catherine drew Sonia into her world, the world of the adult, and shared what she enjoyed, yet perhaps she also recognized that she was less willing to enter the child's world, the world of active children and noisy play and spilled Kool-Aid. In her efforts to help Sonia enter the adult world, she denied Sonia her existence as a child.

Few would disagree about the importance of being literate in our society. During literacy transactions with book sharing, I observed many learning episodes which were characterized by sharing and focusing on something of mutual interest. Catherine clearly intended that Sonia should understand concepts in books. She carefully explained new ideas, and Sonia listened intently. Catherine selected age appropriate learning experiences, and her explanations often transcended the here and now. The pace and flow of information was carefully monitored to ensure success, and Catherine continuously conveyed to Sonia that she was a successful literacy learner. For example, when Sonia asked her mother what a cave was, Catherine not only explained that caves were holes in the rock but added that caves were where bears might hibernate in the winter. Her description transcended the here and now both spatially and temporally. Although my main focus was on literacy transactions, I did notice that Sonia was used to being an only child in adult company and thrived on being the center of attention. On a local shopping expedition to a supermarket she ran around the store chatting to adult workers who obviously knew her well. Catherine had some concerns about how 
she would fit into groups in kindergarten, as she had had little experience in the company of other children. At home she played outside alone. During the orientation week in kindergarten Catherine said to the teacher, "Handle her firmly and all will be well."

\section{Sonia in School}

In September Sonia entered the kindergarten at the local school. Wilford was a small elementary school with a student population of 200. Mr. Brown, the principal, saw the main function of kindergarten as introducing children to formalized schooling. He put a lot of trust in the qualities of his kindergarten teacher to set up a good program and said,

She must be someone who likes children and is adaptable. She should believe in strong home/school communication and be able to work with other people, for example aides and volunteer parents. Anyone who thinks kindergarten is an easy job should try it for a year.

From my observations Sonia's first day was a great success. During play she sang and did a lot of somersaults. She appeared to quickly learn the routine and fitted in well with the other children. The students were introduced to the kindergarten in small groups, so by the time they came together in their large group of 20 , each child had a fair grasp of the daily program. Later in the first week, after recess Sonia seemed to be out of sorts and said, "I don't like recess." This unanswered comment proved to be an early indicator of difficulties with social interactions which were accentuated later.

Except on special days or field trips, the school day consisted of circle, gym, and work time before recess, and center time and circle before noon. During the first week the work time consisted of a worksheet on the number 1 . Sonia followed the directions and completed the sheet quickly. On the instruction of her teacher, Mrs. Johnson, she had written her name in upper and lower case letters. She appeared to be eager to please the adult in charge. When the sheets were completed and handed in for correction, Sonia rushed for a puzzle and was joined by John who wanted to help her. She refused his offer, and he chose one of his own. Later she called to him, "Look what I've done," and he replied curtly, "Who cares?" Mrs. Johnson added, "That child is just not prepared to share this morning." The teacher's statement implied that Sonia was unwilling to share that morning. In reality, sharing with other children was a rare phenomenon for Sonia who, in general, played on her own. She was extremely fond of puzzles, art 
work, and drawing on the blackboard. Also, on several occasions she went to the listening center to read a book, or she chose a book from the library corner. Occasionally she was observed matching her oral version of a story with the pictures. She spent very little time with water, sand, wood, construction toys, and dramatic play, activities which she didn't do at home and which often involved group participation.

At the beginning of the school year, Sonia was keen to look at books. If she was in the middle of reading a book at tidy-up time, she was upset when she was told to put it away. At times, she ignored the teacher and continued to look at the books. She also wrote her name, her phone number, and some number equation which had been taught at home on the blackboard. As an early writer she approximated the form of the equation but did not appear to understand the meaning of the symbols.

Each center time was followed by a circle time. A special tidyup tune was played by Mrs. Johnston on the piano. I observed that Sonia found circle to be a difficult procedure. Being used to initiating conversations with her parcnts during book sharing, she attempted to do this in the school setting. She was constantly reprimanded and told, "Sonia, story time is a quiet time. If you can't be quiet, you will be leaving." However, not all the children's comments led to reprimands. For example, at one point, in reference to a line in the story, when another child asked, "What's a whack?" she was ignored and the story continued. Mrs. Johnston set the social rules. Some children were allowed to break the rules but other were not. Interactions during this process were usually initiated by Mrs. Johnston and required a single specific response from the child.

Often during circle Sonia refused to sit down and said, "I don't like sitting down. I wanna read a book. I just gotta move around. I brought a book for show and tell and you didn't even read it." Mrs. Johnston would tell her to sit on the floor, and if that failed she was pulled to the floor. Sonia, who was used to long explanations from her mother and father, often looked hurt and puzzled when her questions were silenced or left unanswered. This, coupled with her lack of group experience, may have contributed to her disruptive social behavior at circle time and during other large-group activities.

Mrs. Johnston considered work time which preceded recess to be an important component of her program, and Sonia worked well on her own. Although the children were told that work time was a quiet time, the dominant feature of this period was 
the conversation of the children. Friends were chosen to sit beside. One day when two other children, Susan and Brian, were working at the same table as Sonia on a number worksheet with an arrow on it, the following conversation was noted. Susan cut out the worksheet and made a spider with the scraps and said, "Walk, walk, walk, baby spider. What's the arrow for?" "The boxes go here,"replied Brian. "See where the arrow is pointing. It's supposed to go here." Sonia said, "Remember the Planetarium (field trip)? We saw an arrow (light arrow)." At the mention of arrow, two other children burst into song singing "Me and My Arrow" with great gusto. Sonia glared at them and said, "I don't like that song and I don't like everybody here." The singers looked hurt and puzzled.

Sonia also had difficulties at gym. She often found it difficult to find a partner and constantly shouted, "Watch me, Mrs. Johnston, watch me!" One day, for no apparent reason, John pushed her. She screamed and Mrs. Johnston said, "That is what it is like to be pushed, Sonia. Hopefully you will learn your lesson." At no time did I as participant observer notice Sonia pushing or hitting another child.

As the term progressed Sonia's behavior deteriorated, as did the behavior of the children toward her. On snowy days she often returned from recess in a distressed state screaming, "They all ran after me. They punched me in the stomach. Someone stood on my face." When the class was asked who hit first they inevitably said, "Sonia." The teacher's and aide's responses were often judgmental: "This is your problem, Sonia. You had it coming." No explanation was sought or attempt made to talk with Sonia or her parents.

By November I observed that Sonia hated school and on arrival often exclaimed, "Know what? I want to throw up." November was also the time for parent interviews. One of the first parents to be interviewed expressed a concern about her son fighting with Sonia. She said that her son claimed, "We got Sonia. She beat me up so we beat her up. She tried to run but we get her and she screams, 'Leave me alone! Leave me alone." The teacher's response to this was that Sonia was having social and emotional problems.

\section{Take the Blame}

Sonia's parents had no knowledge of any school problems and so were shocked when their interview opened with the statement, "Sonia is all right intellectually, but she has social problems. She does not take responsibility for her actions." Both parents were confused and translated the whole affair as 
"Sonia misbehaves at school." Like the teacher, they took a judgmental stance and spoke to her, stressing that she must be a good girl and do as she is told. When I pointed out to the parents the problems Sonia was having at recess and after school, they observed her playing and walked her home from school. She was protected outside, but the social situation in the classroom did not alter and no one helped her to participate in group activities. Attempts made by children to befriend her were rebuffed. Many of the children in this setting had brothers and sisters and had attended various playgroups before kindergarten. A large number also attended day care. They were used to small and large group activities and easily adapted to the social rules of the kindergarten. Sonia did not have this experience, and it appeared that no one realized this nor took time to show her how to participate. At no time during the school year did her parents invite any of the kindergarten children to their home, and the gap between home and school was not bridged. She came to school alone, played alone all morning, and went home alone to adult company, usually that of her mother.

In the second term the kindergarten program structure generally remained unchanged. There were, however, major changes in literacy activities. At both circle and work time there was now a focus on the letters of the alphabet. This focus on the letters of the alphabet and the sounds they made was simplistic for Sonia who usually "read" favorite stories by looking at the pictures and making up the text. Sonia's number of sight words had increased with her collection of favorite words. She could read the following words: Sonia, queen, dad, mom, snow, dog, bird, mouse, cat, lemon, drop, David, Susan, and the names of three other children at school.

By May, despite her continued liking of story time both at school and at home, she was not showing an interest in reading to her teacher or taking books home from the class library. In the school setting, Sonia's interest in print appeared to decline throughout the year. As late as March, Mrs. Johnston reported her social behavior to still be problematic: "Sonia has been dreadful for the last two weeks, screaming and shouting and having temper tantrums." She had difficulty with the alphabet lessons both at circle and work time and often could not read the words she copied on the back of her worksheets. At free play she continued to play on her own at painting and table games.

For Sonia, literacy interactions at home differed greatly from those at school, and the differences caused great anguish. In- 
teractions in these two settings differed in that in the home Sonia was the main initiator of literacy learning, whereas in the kindergarten the teacher was the initiator and Sonia's attempts to initiate were not welcomed. Sharing and reciprocity were clearly observable between Sonia and her parents. In the school setting, however, she had to participate in a predetermined program, the construction of which was not mutually shared between herself and her teacher. It was demanded that she passively accept instructions in the classroom although she did not understand the rationale behind the activity. Not knowing the teacher's goals, she did not share in them. Interactions in the school in general were of a stimulus response type with no links made to the past or the future.

In kindergarten Sonia was expected to complete work chosen on the basis of reading readiness despite the developmental level. Pacing often did not match her learning abilities. In her home she was constantly praised for any success. This may have meant that she depended on praise to encourage her learning. If so, this was soon dispelled in kindergarten where errors were corrected without explanations and behavior was not regulated to ensure success.

As the following conversation with a student teacher shows, Sonia was used to individual attention at home and craved this at school.

Sonia: Sit beside me, Jane.

Jane: Each day I sit beside someone different.

Sonia: Well, I'm different.

She was different, but the difference was not acceptable. The teacher, in an attempt to socialize her, showed her a film about being a good friend, but no explanation or discussion accompanied the viewing. The teacher unsuccessfully attempted to mediate her classroom behavior, but their interactions were of a stimulus response type and were authoritarian as the following dialogue shows:

Mrs. Johnston: All right, Sonia, if you speak again you will have to leave. I'm not putting up with this. You'll go to the office.

Sonia: My mom's not well. She's in hospital.

Mrs. Johnston: Please don't yell. I don't like to be yelled at. Neither do you.

The teacher responded to the volume of voice and not to the message. Sharing was lost, and the vital component of reciprocity was not observable. Except during story time, Sonia 
found it difficult to sit still, "I just gotta move around." On one occasion during story time, she was removed to a corner where she screamed, "I always do it wrong, I always do it wrong."

There did not appear to be an attempt by the teacher to access and respect the inner life of this child. Sonia did not fit like the other students. She disrupted the lessons and experienced pain, distrust, anger, rejection, aggression, and complacency. Rather than carefully teaching her in a mediational sense how to behave, deviations from the expected social behavior were attacked in the hope of eliminating them.

In the kindergarten where there is no prescribed curriculum, the timetable dominated. The majority of literacy events were teacher initiated. When Sonia tried to interact in the manner that she did at home, most of her attempts to initiate were unsuccessful. Most interactions involved an initiation by the teacher, a response by the child, and an evaluation by the teacher. The basic form and content of the literacy program were based on the teacher's predetermined curriculum. The choice of books read to the children was not negotiated, and the teacher's agenda was not abandoned in favor of the child's agenda.

Another striking characteristic was the fairly rigid adherence to a time schedule. The practice of allowing a child to complete an activity was not utilized in Sonia's classroom and often produced conflict between Sonia and the teacher when she was denied the choice of completing a reading session or the opportunity to bring an activity to a natural conclusion. Thus she was denied the satisfaction of a completed personal purpose.

Because Sonia came to kindergarten with numerous concepts about print, books, reading, and writing, the literacy program provided a minimal cognitive challenge. The teacher made little attempt to build knowledge on what she had already established in her home. This lack of bridging shows a disrespect for the child's world. As Bruner has noted, if we separate learning from "the context of immediate relevant activity," we may be in the dangerous position of making classroom learning "an empty formalism" with no impact on cognition (Wells, 1981, p. 265). We run the risk of producing the boredom and frustration of inert ideas (Whitehead, 1967).

\section{Responsibility}

From this portrait we see that Sonia's self was in opposition to the teacher's understanding and behavior. The question is 
whether the teacher, the child, and the parents have the resources to mediate this opposition.

First let us examine the issue from the teacher's perspective. Literally millions of children and thousands of adults are thrust together in our school systems. This milieu demands social as well as intellectual intimacy. Given the inequity of the position of student and teacher, I would expect the teacher to make a greater effort than the student to understand the other. Teachers should constantly be aware of their opportunities to exert power over the life of the child and mold that child to fit the good society as we see it. This process is, of course, not one sided. Teachers must look below the surface of behaviors and try to see the world from the child's perspective. Does the child have a voice in his or her own education, or will the child's voice be silenced for efficiency and order? The teacher in this study did take definite steps to challenge Sonia's behavior, but these steps were not mediational in nature and in general were characterized by confrontation. Sonia was isolated as a troublemaker, and the tensions built up with the teacher remained when she was alone with her peers. The teacher, the product of a teacher education system which focused on within-child faults, searched old psychological textbooks for possible causes of Sonia's behavior rather than listening to Sonia, talking with her parents, and realizing the importance of the child rather than the fear of loss of control. The teacher's role is not to coerce children to do as you want them to. "Fear is the inseparable companion of coercion, and its inescapable consequence" (Holt, 1964, p. 179). Sonia came to school enthusiastic and willing to learn. By the end of her kindergarten she was so filled with fear and apprehension that she lost her enthusiasm for schooling. The patterns of interaction she encountered were damaging to her emerging self.

From the child's perspective, social learning results, to a large extent, from group activities. Unused to participating in groups of her own age before school, Sonia had great difficulty in adjusting to participating in group activity in school. In kindergarten she almost always engaged in solitary play and did not take ideas from other children or attempt to contribute to the play of others. In the authoritarian climate of the classroom her behavior oscillated between aggression and submissive dependency. By five years of age a child usually can take part in simple games such as snakes and ladders, card games, and party games (Sandstrom, 1966). This was not so for Sonia who had not learned to be social in a peer group setting; rather she had learned to use her initiative to make herself more en- 
dearing to adults as in the shopping episode (Lowe, 1972). These attempts failed in kindergarten where she was now one of 20 children seeking the attention of one adult who was obviously irritated by her persistent calls to "Look at me." She tried to be good but never knew what that meant. She had been a good girl before school; why was she now bad? She was behaving just as she always had done.

From the parents' perspective, they had some concerns about how Sonia would fit into kindergarten, but they did not take any steps to ease this fitting in by encouraging Sonia to play with other children outside school hours or by checking with the school about how Sonia was doing. Communication was left until the parent/teacher interview in November. This interview proved disastrous on several fronts. The parents were shocked to hear that Sonia was having social and emotional problems and that these were due to the fact that she did not take "responsibility for her actions." They could not understand this statement, never mind do anything about it, but instead of trying to find out more, for example, by observing in the classroom, they simply told Sonia to be a good girl. It appeared that not only students but parents succumbed to school authority. For both parents, schooling had not been a positive experience and as a result they were nervous as soon as they entered the building. I am sure that fear was their dominant emotion. Here they were on ground where the teacher was expert. They did not see themselves as having a role in supporting their child. As at home, the adult world view predominated and the word of the adult teacher went unquestioned. What I witnessed during this parent/teacher interview was human beings talking at one another but not communicating.

Could this situation have been improved or changed? I believe so, providing that all the players were involved and shared the desire to recognize that children vary in social as well as intellectual learning before school. These differences should be valued and looked on as a rich base for cultural growth. Despite numbers in classes we must take time to listen to individual children and from close observation decide when it is appropriate to mediate some aspect of one culture to a particular child. Social behavior is just as learned as literate behavior. The promotion of growth requires teaching, mediation, and a variety of opportunities to practice new learnings. With such support I feel confident that Sonia could have moved from solitary to cooperative play without losing her sense of self. Indeed, the self could be greatly enriched by cooperation with her peers. The kindergarten, with its focus on play and 
group activities, could provide an excellent opportunity for children such as Sonia to learn to be social. In one example, Wendy helped Mike to learn these rules. While playing at the house of one of the children, Mike stood in front of the television screen blocking Wendy's view. She gently said, "Mike, please may you move?" When this didn't work, she got his music box, wound it up and said, "Come and get it Mike." Later she helped him with an alphabetic game, saying, "Mike, do you know where it goes?" She helped him to put a piece in the correct position and then said, "Good boy for trying" and the play continued. Rather than focusing on what Sonia lacked, learning could have facilitated growth which would have been transferable to many social settings. "Fifteen months of fieldwork intensified my belief that what people become is largely a function of what they have had an opportunity to experience" (Eisner, 1981, p. 466). The secret of learning is not found in confrontation, obstruction, or denial through labeling, but rather in inclusion, cooperation, the provision of easy access to knowledge, and attempts to build on our future-that is, our children.

\section{References}

Eisner, E. (1981). Mind as cultural achievement. Educational Leadership, 38, 466-471.

Holt, J. (1964). How children fail. London: Pitman.

Lowe, G.R. (1972). The growth of personality: From infancy to old age. Harmondsworth, UK: Penguin.

Sandstrom, C.I. (1966). The psychology of childhood and adolescence. Harmondsworth, UK: Penguin.

Wells, G. (1981). Learning through interaction: The study of language development. Cambridge: Cambridge University Press.

Whitehead, A.N. (1967). The aim of education. London: Free Press.

\section{Bibliography}

Doake, D.B. (1981). Book experiences and emergent reading behavior.

Unpublished doctoral dissertation, University of Alberta.

Feuerstein, R., Rand, Y., Hoffman, M., \& Miller, R. (1980).

Instrumental enrichment. New York: University Park Press.

Freire, P. (1970). Pedagogy of the oppressed. New York: Continuum Publishing.

Freire, P. (1982). Education for critical consciousness. New York:

Continuum Publishing.

Piaget, J. (1965). Growth of thought. In W. Kersen (Ed.), The child.

New York: Wiley. 